\title{
Effect of different time intervals of light emitting diode therapy application on muscle fatigue
}

\section{Efecto de diferentes intervalos de tiempo de la aplicación de la terapia con diodos emisores de luz sobre la fatiga muscular}

\section{Mai Raouf Mohamed Rageh ${ }^{1 *}$, Abeer Abdelrahman Yamany ${ }^{2}$, Hamada Ahmed Hamada ${ }^{3}$, Rania Reda Mohamed ${ }^{4}$}

${ }^{1}$ Assistant Lecturer of physical Therapy, Basic Science Department, Faculty of Physical Therapy, Cairo University, Egypt; mai.rageh@cu.edu.eg

${ }^{2}$ Professor of Physical Therapy, Basic Science Department, Faculty of Physical Therapy, Cairo University, Egypt; Abeer.Yamany@pt.cu.edu.eg

${ }^{3}$ Assistant Professor of Biomechanics and Ergonomics, Biomechanics Department, Faculty of Physical Therapy, Cairo University, Egypt; Hamada.ahmed@pt.cu.edu.eg

${ }^{4}$ Lecturer of physical Therapy, Basic Science Department, Faculty of Physical Therapy, Cairo University, Egypt; raniareda22@cu.edu.eg

* Correspondence: Mai Raouf Mohamed Rageh; mai.rageh@cu.edu.eg

\begin{abstract}
This study aimed to identify the near-infrared (NIR) light emitting diode (LED) time response on isokinetic peak torque of elbow flexors. This was a prospective, randomized, single blind, pre-test post-test, and placebo-controlled crossover study. Forty-five healthy non-athletes were assigned at random to 3 groups equally: 5 minutes, 1-hour and 5-hours groups. Each group $(n=15)$ had at the first session $890 \mathrm{~nm}$ wavelength NIR-LED, either in active or placebo conditions, prior to exercise that provokes fatigue ( 5 minutes, 1 hour, or 5 hours). After an interval of 7 days, the second NIR-LED condition was applied at the second session. The assessment of isokinetic peak torque was done at base line and post exercise in each session using isokinetic dynamometer. There was no significant difference between groups and between conditions in isokinetic peak torque $(p>0.05)$. Isokinetic peak torque decreased significantly post treatment compared with pretreatment $(p<0.01)$ in all groups, but
\end{abstract}


Rageh et al.

the 5 minutes group showed the least percent of decrease. In conclusion, NIR-LED can most probably resist muscle fatigue with the parameters used in this study if it is employed 5 minutes before exercise.

\section{KEYWORDS}

Light emitting diode; infra-red wavelength; peak torque.

\section{RESUMEN}

Este estudio tuvo como objetivo identificar el momento idóneo de aplicación del diodo emisor de luz (LED) del infrarrojo cercano (NIR) en la potencia máxima isocinética de los flexores del codo. Este fue un estudio cruzado prospectivo, aleatorizado, simple-ciego, con pre-test y post-test, y controlado con placebo. Se asignaron al azar cuarenta y cinco no deportistas sanos a 3 grupos por igual: grupos de 5 minutos, 1 hora y 5 horas. Cada grupo $(\mathrm{n}=15)$ tuvo en la primera sesión NIR-LED de $890 \mathrm{~nm}$ de longitud de onda, en condiciones activas o placebo, antes del ejercicio que provoca fatiga ( 5 minutos, 1 hora o 5 horas). Después de un intervalo de 7 días, se aplicó la segunda condición NIR-LED en la segunda sesión. La evaluación de la potencia máxima isocinética se realizó antes y después del ejercicio en cada sesión utilizando un dinamómetro isocinético. No hubo diferencias significativas entre los grupos y entre las condiciones en la potencia máxima isocinética $(p>0.05)$. La potencia máxima isocinética disminuyó significativamente después del tratamiento en comparación con el pretratamiento $(\mathrm{p}<0.01)$ en todos los grupos, pero el grupo de 5 minutos mostró el menor porcentaje de disminución. En conclusión, lo más probable es que NIR-LED pueda resistir la fatiga muscular con los parámetros utilizados en este estudio si se emplea 5 minutos antes del ejercicio.

\section{PALABRAS CLAVE}

Diodo emisor de luz; longitud de onda infrarroja; potencia máxima.

\section{INTRODUCTION}

Muscle fatigue is identified as the reduction in the muscles' capability to develop force or power throughout physical activities (Enoka \& Duchateau, 2008). Muscle fatigue can be frequently experienced, although the complexity of this process is not fully distinguished. The usually detected attributes of skeletal muscle fatigue are declined muscle strength, deficient motor skills and consequent muscular pain (Green, Langberg, Skovgaard, Bülow \& Kjær, 2000). 
Rageh et al.

Muscle fatigue exposes operators to more risks of overexertion, and cumulative muscle fatigue may lead to musculoskeletal disorders (Chaffin, Andersson \& Martin, 2006; Armstrong, Buckle, Fine, Hagberg, Jonsson \& Kilbom et al., 1993). The additional reinforcing joint structures are subjected to extraneous loading because the fatigued muscles cannot produce the needed force. This may lead to failure of the tissues that support the joints and in consequence cause injuries. Altered neuromuscular control emerges with fatigue, which influences the joint sense of position and kinesthesia (Ballantyne \& Shields, 2010).

Many interventions have been led to promote muscle functioning or impede muscle fatigue signals, such as massage, warm-up, use of compression garments and cryotherapy (Calleja-González, Terrados, Mielgo-Ayuso, Delextrat, Jukic \& Vaquera, et al., 2016; LaBella, Huxford, Grissom, Kim, Peng, Christoffel, 2011; Weerapong, Hume, Kolt, 2005). However, the benefits of such methods are still uncertain and rather theoretical (LaBella, Huxford, Grissom, Kim, Peng, Christoffel, 2011; Weerapong, Hume, Kolt, 2005).

Photobiomodulation therapy (PBMT) comprises low-level laser therapy (LLLT), as well as light-emitting diode therapy (LEDT), which is a method extensively used by physiotherapists in the process of rehabilitation, and there are numerous indications of its positive influence on tissue repair (Pinheiro, 2009), pain (Fulop, Dhimmer, Deluca, Johanson, Lenz \& Patel et al., 2010) and inflammation (Bjordal, Lopes-Martins, Joensen \& Iversen, 2010).

Most of near infra-red (NIR) light therapy researches were focused on the ability of PBMT to support soft tissue healing (Larkin-Kaiser, Christou, Tillman, George \& Borsa, 2015). There were several studies on the ability of NIR light therapy, during and after resistance exercise, in alleviating skeletal muscle fatigue and resisting strength loss (Baroni, Junior, De Marchi, Lopes, Salvador \& Vaz, 2010; Leal Junior, Lopes-Martins, Dalan, Ferrari, Sbabo \& Generosi et al., 2008; Junior, LopesMartins, Baroni, De Marchi, Taufer \& Manfro et al., 2009; Leal, Lopes-Martins, Frigo, De Marchi, Rossi \& De Godoi et al., 2010; Leal Junior, Lopes-Martins, Vanin, Baroni, Grosselli \& De Marchi et al., 2009). Some authors have shown evidence of light therapy's capability in blood circulation enhancement, resulting in an improvement in tissue oxygenation (Samoilova, Zhevago, Menshutina \& Grigorieva, 2008; Maegawa, Itoh, Hosokawa, Yaegashi \& Nishi, 2000; Larkin, Martin, Zeanah, True, Braith \& Borsa, 2012). 
Rageh et al.

\section{LITERATURE REVIEW}

It was noted that healthy untrained participants' irradiation by PBMT prior to exercise significantly improved $\mathrm{VO}_{2}$ max both in absolute and in relative measures, in addition to the time to reach fatigue (De Marchi, Junior, Bortoli, Tomazoni, Lopes-Martins \& Salvador, 2012). On the other hand, while its results are well established, there is a multifaceted variety of parameters as wavelengths, application patterns, dosages, and treatment time windows (Lanferdini, Bini, Baroni, Klein, Carpes \& Vaz, 2018).

It was reported in literature that the main guideline for applying PBMT for muscle preconditioning was the muscle's irradiation of 5 minutes before exercise, in order to resist fatigue and increase functioning (Baroni, Junior, De Marchi, Lopes, Salvador \& Vaz, 2010; Baroni, Leal Junior, Geremia, Diefenthaeler \& Vaz, 2010; Ferraresi, de Brito Oliveira, de Oliveira Zafalon, de Menezes Reiff, Baldissera \& de Andrade Perez, et al., 2011; Higashi, Toma, Tucci, Pedroni, Ferreira \& Baldini, et al., 2013; Rossato, Dellagrana, Lanferdini, Sakugawa, Lazzari \& Baroni, et al., 2016; Miranda, Vanin, Tomazoni, Grandinetti, de Paiva \& Machado, et al., 2016). While positive gains have been identified, such as improved time to fatigue and maintenance of strength competence, the best implementation period for the procedure may not be immediately prior to the fatiguing exercise (Leal Junior, Lopes-Martins, Dalan, Ferrari, Sbabo \& Generosi et al., 2008).

This perspective was reinforced when a muscular pre-conditioning protocol, delivered to qualified volleyball competitors 40 to 60 minutes before the formal match, was able to significantly reduce creatine kinase concentrations in the bloodstream, which reflects reduction of muscle damage. This study indicated that muscle pre-conditioning applied 3 to 5 minutes prior to the exercise might not necessarily be the best time interval (Ferraresi, Dos Santos, Marques, Zangrande, Leonaldo \& Hamblin et al., 2015).

Furthermore, it was observed that PBMT applied 3 or 6 hours before evaluation improved the potential of the mitochondrial membrane and Adenosine Triphosphate (ATP) manufacture of myotubes of muscle cells of mouse in comparison to 5 minutes or 24 hours before assessment(Ferraresi, Kaippert, Avci, Huang, de Sousa \& Bagnato et al, 2015). Additionally, it was recorded that PBMT applied 6 hours prior to exercise improved the findings during fatigue test and increased the content of ATP in an animal model experiment compared to PBMT applied 5 minutes, 3 hours, or 24 hours before evaluation (Ferraresi, de Sousa, Huang, Bagnato, Parizotto \& Hamblin, 2015). 
Rageh et al.

Governed by the results of these two previous experimental investigations, a clinical trial on healthy and physically active participants pointed out that PBMT applied immediately before (i.e. 5 minutes), and combined with 6 hours before a high-level intensity exercise protocol, was able to reduce the strength fall than when applied immediately or 6 hours before separately (Rossato, Dellagrana, Sakugawa, Lazzari, Baroni \& Diefenthaeler, 2018). On the contrary, the time response of PBMT by LED was examined at 5 minutes, 1 hour, 3 hours, and 6 hours before exercise, showing that the PBMT using LEDs was not efficient in fatigue resistance of elbow flexor muscles at any of these time intervals, in healthy and substantially active males (Abreu, Dos Santos, Fonsati, Marques \& Ferraresi, 2020).

These contradictory findings bring up some remarkable question that needs to be resolved by further research: What is the best time interval separating LED application and exercise? This query creates a knowledge gap in this area that prompts researchers' and clinicians' incapability to precisely detect the best time to apply PBMT, especially NIR LED, before exercise to improve muscle's resistance capability. Therefore, the purpose of this study was to identify the effects of different time intervals of pre LEDT application (5 minutes, 1 hour and 5 hours) on isokinetic peak torque (IKPT) of elbow flexor muscles as an indicator of muscle's fatigue resistance potential.

\section{METHODS}

\subsection{Study design}

A prospective, randomized, single blind, pre-test, post-test, placebo-controlled crossover study was carried out. Prior to commencing the study, ethical approval was fulfilled from the institutional review board at the Physical Therapy Faculty of Cairo University (NO: P.T.REC/012/002480). It was implemented between October 2020 and December 2021. The study protocol was recorded online on ClinicalTrials.gov (NCT04367727).

\subsection{Participants}

A sample of convenience, non-probability type, of forty-five participants, was enlisted through online announcement at the Faculty of Physical Therapy of Cairo University. Informed consent was taken from each participant after interpreting the research aims and procedures, ensuring their privacy through coding of all their data.

Participants were incorporated if their age was from 20 to 30 years, having a body mass index of less than or equivalent to $25 \mathrm{~kg} / \mathrm{m}^{2}$ (Mehta \& Cavuoto, 2017) and if they were healthy physically 
Rageh et al.

active and non-athletic. They were ruled out if they had a former musculoskeletal type of injuries in the wrist, elbow, or shoulder vicinities, if they were accustomed to strengthening exercise several times weekly or had used any category of complementary dietary nutrients or agents of pharmacological nature through the preceding 2 months (de Almeida, Lopes-Martins, De Marchi, Tomazoni, Albertini \& Corrêa et al., 2012).

To avoid type II error, sample size calculation was performed using G*POWER statistical software (version 3.1.9.2; Franz Faul, Universitat Kiel, Germany) [F tests- MANOVA- special effects and interaction, $\alpha=0.05, \beta=0.2$, effect size $=0.27]$ and revealed that the appropriate sample size for this study was $\mathrm{N}=45$.

\subsection{Randomization and cross over design procedures}

Randomization was carried out by a simple pulling of a card, which determined the duration of the sessions ( 5 minutes, 1 hour or 5 hours), then pulling one more card to determine if active or placebo LEDT conditions should be given at the first session. At the second session participants were crossed over to receive whatever condition was not given at the first session.

Participants were crossed over in a two-session procedure, performed 7 days apart, to compare findings after active and placebo LEDT implementation for every participant. In this way, all participants underwent the same procedures, but in a different sequence, consistent with randomization procedures.

The code that was pulled was delivered to a researcher who prepared the LEDT sessions consequently to either an active or placebo LEDT mode. The researcher was instructed not to reveal the type of treatment given to the participants.

\subsection{Interventions}

Following randomization, procedures were carried out completely in the laboratory of isokinetic at the Faculty of Physical Therapy of Cairo university. The participants received active (60 Joules) or placebo (0 Joule using a switched off device) NIR-LED randomly before exercise that provokes fatigue: 5-minute group ( $\mathrm{n}=15$; NIR-LED employed 5 minutes before exercise), 1-hour group $(\mathrm{n}=15$; NIR-LED employed 1 hour before exercise) and 5-hour group ( $\mathrm{n}=15$; NIR-LED employed 5 hours before exercise). 
Rageh et al.

Consistent careful procedures were done in 2 separate sessions, which were spaced out by an interval of 7 days, so that each participant received one of the 2 LED conditions (active or placebo) at each session and, to minimize the impact of diurnal variations, all procedures were conducted at similar time of day and identical day of week. All study procedures are shown in Figure 1:

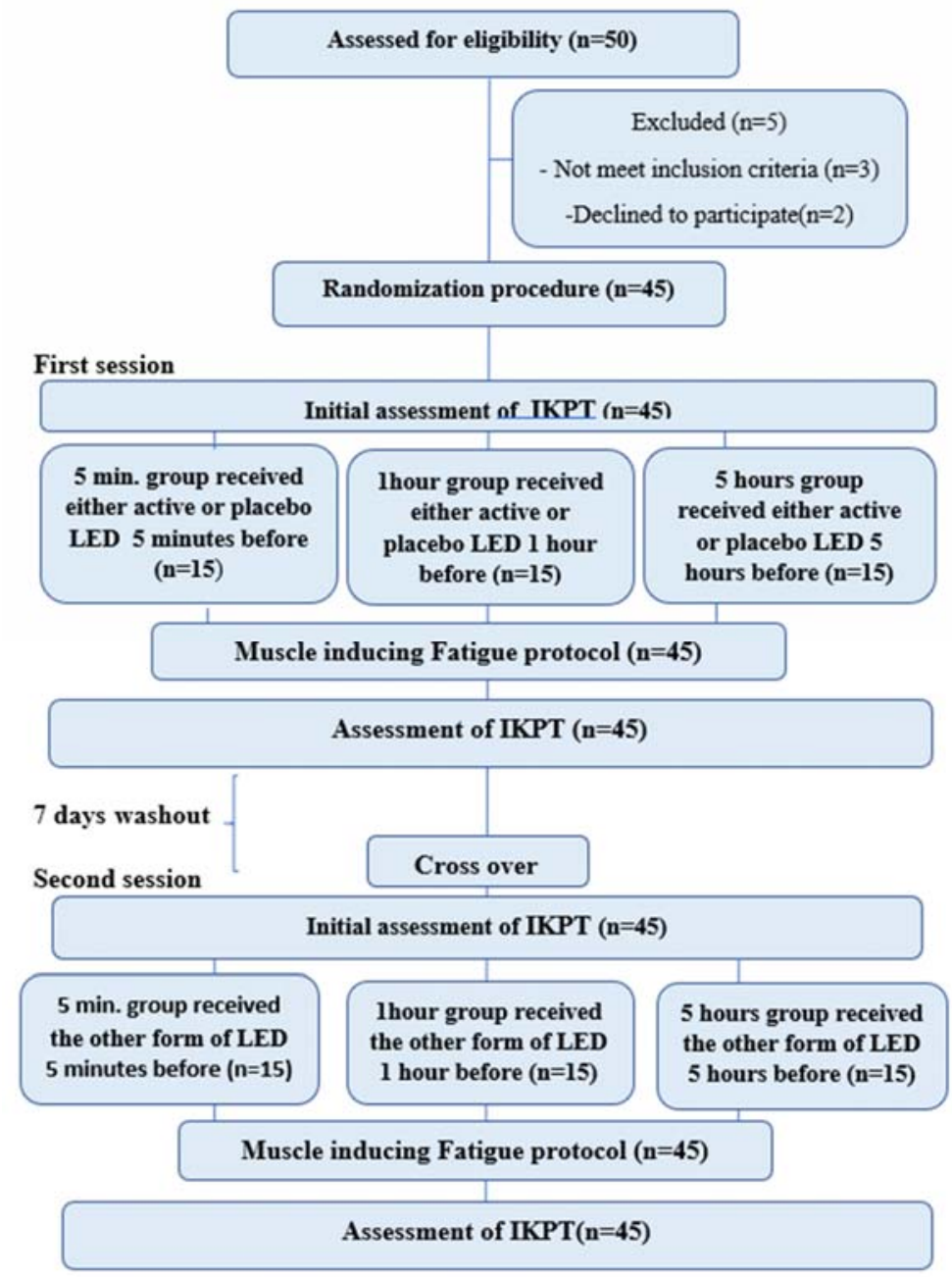

Figure 1. CONSORT chart showing the procedures of the study

LEDT was applied using 120 commercial diodes (Anodyne Therapy System, LLC, model 120, MH043463) arranged in parallel on 2 flexible array pads of neoprene material (Figure 2A) that produce a wavelength of $890 \mathrm{~nm}$ NIR. NIR-LEDs are commonly used in clinical physiotherapy practices (Enwemeka, 2009; Enwemeka, 2000). The parameters of application were selected in line with the most recent proposed parameters in the literature (Leal-Junior, Lopes-Martins, Bjordal, 2019). Table 1 shows the applied parameters. 
Rageh et al.

Firstly, the overlying skin was cleaned with alcohol, then with participants' arm rested, unilateral application of active or placebo NIR-LED was done over elbow flexors of the dominant upper limb, by the therapist, in direct skin contact via 2 flexible pads supported by straps at the center of the elbow flexor muscles ventral surface (Leal, Lopes-Martins, Frigo, De Marchi, Rossi \& De Godoi, et al., 2010) (Figure 2B). Blinding of participants was sustained by using opaque glasses during implementation procedures, which also helped in eyes securing from LEDT irradiation.

Table 1. Light-emitting device optical parameters

LEDs’ number : 120

Pads' number: 2

Frequency: $292 \mathrm{~Hz}$

Device's overall optical power: $1800 \mathrm{~mW}$ (15 mW per diode)

Diode's area: $0.2 \mathrm{~cm}^{2}$

Device's efficient irradiation area: $45 \mathrm{~cm}^{2}$

Diode's power density: $75 \mathrm{~mW} / \mathrm{cm}^{2}$

Average power of the 2 pads: $960 \mathrm{~mW}$

Time of irradiation in seconds: 57 seconds.

Energy density through 57 seconds: $1.33 \mathrm{~J} / \mathrm{cm}^{2}$ (2.5 J/diode)

Device's overall energy at 57 seconds: $63.06 \mathrm{~J}$

Hz: Hertz, mW: milliwatt, J: joule.

Through the two sessions there were no variations in any of the procedures except for placebo state, which was done in the same way as active one, except with the device shut down. 
Rageh et al.

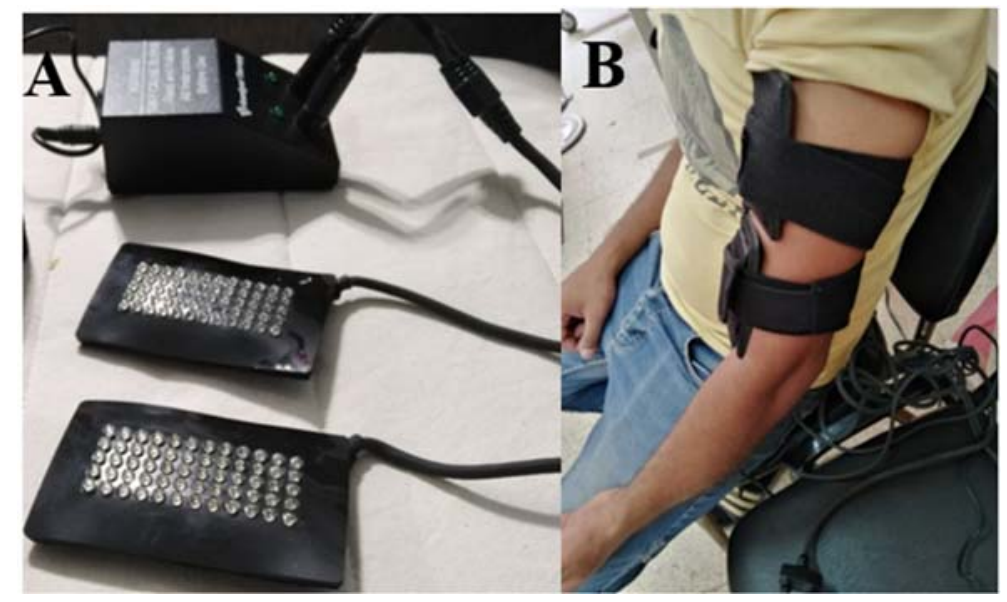

Figure 2A. Flexible arrays of LED used in the study. B. Positioning of the device on the elbow flexors during irradiation procedure

A dynamometer (Biodex system 3; Biodex Medical, Shirley, New York), which was calibrated on a daily basis, was used for isokinetic peak torque assessment and fatigue induction, that is used to objectively assess muscle functioning or to evaluate the efficacy of different treatments frequently (Amaral, Marinho, Ocarino, Silva, Souza \& Fonseca, 2014). Participants sat on the chair following the instructions' manual, with the trunk secured by belts to counteract any offsetting movements. The dynamometer rotational axis was aligned with the elbow joint axis.

Isokinetic peak torque (IKPT): It was measured at base line (pre-LED application) and immediately post fatiguing exercise. In the isokinetic mode, five contractions were carried out. Participants were requested to move the elbow in flexion and extension through the complete motion range $\left(0^{\circ}-120^{\circ}\right)$, as much as possible, strongly and quickly for each repetition, and to implement the greatest possible strength during elbow flexion and opposing elbow extension introduced by the dynamometer from the beginning to the end. The most powerful contraction of the 5 estimates was reported as the IKPT in newton meters and was considered the participant's highest power generation capability at base line (pre-value). Verbal and visual feedbacks were provided throughout torque assessment to encourage maximal effort from all participants.

Fatigue provoking exercise protocol (FPEP): After IKPT assessment, active or placebo LED was applied, followed by fatigue provoking exercise protocol (FPEP). Force reduction was provoked using continued maximal concentric and eccentric elbow flexors' actions. Participants were guided to do 3 sets of 20 repetitions of maximal concentric and eccentric contractions. This exercise protocol has been previously employed and imitates the cellular activities observed with acute exercise sessions (Borsa 
Rageh et al.

\& Sauers, 2000). The angular velocity was adjusted at 45 degrees/sec for concentric actions and 60 degrees/sec for eccentric actions. Each participant was guided to do repetitions "as powerful as possible". Oral and visual feedbacks were given throughout the exercise protocol.

Post fatigue procedures: Participants underwent a post evaluation of IKPT exactly 30 seconds after the FPEP, following the same procedures as before FPEP with the same feedback given by the therapist. The maximum power generating capacity was considered as the participant's after exercise value (post value). The change in torque was measured (change between the baseline and post-fatigue values) and was compared within and among groups at the 2 sessions.

\subsection{Data analysis}

Descriptive statistics and MANOVA test were done for comparison of participants characteristics among groups. Chi- squared test was used for comparison of sex allocation among the three groups. Normal distribution of data was checked using the Shapiro-Wilk test for all variables. Levene's test for variances' homogeneity was performed to examine the homogeneity among groups. Investigation of the effect of time (pre versus post), the effect of condition (active versus placebo) and the effect of treatment (among groups), as well as the interaction effect of values of the mean of isokinetic peak torque, was performed by $3 \times 2 \times 2$ MANOVA of mixed design. Consequent multiple comparisons were assessed by tests of post-hoc type using the Bonferroni type of correction. The level of significance for all statistical investigations was adjusted at $\mathrm{p}<0.05$. All statistical exploration was operated through the statistical package for social studies (SPSS) version 20 for Windows (IBM SPSS, Chicago, IL, USA).

\section{RESULTS}

\section{Participants' characteristics}

Table 2 shows the participants' characteristics of the 5 minutes, 1 hour and 5 hours sessions. There was no significant variation among groups in age, weight, height, and BMI ( $p>0.05)$. Also, there was no significant variation in sex distribution among groups $(p>0.05)$. 
Table 2. Basic characteristics of participants

\begin{tabular}{|c|c|c|c|c|}
\hline & $\begin{array}{l}5 \text { minutes } \\
\text { group }\end{array}$ & $\begin{array}{l}\text { 1-hour } \\
\text { group }\end{array}$ & $\begin{array}{l}5 \\
\text { group }\end{array}$ & $\underset{*}{\text { p-value }}$ \\
\hline $\begin{array}{l}\text { Age } \\
\text { (years) }\end{array}$ & $25.66 \pm 2.79$ & $25.86 \pm 2.89$ & $25.06 \pm 2.96$ & 0.733 \\
\hline $\begin{array}{l}\text { Weight } \\
\text { (kg) }\end{array}$ & $67.80 \pm 5.87$ & $66.53 \pm 6.18$ & $64.93 \pm 6.35$ & 0.447 \\
\hline $\begin{array}{l}\text { Height } \\
\text { (cm) }\end{array}$ & $166.5 \pm 5.59$ & $165.13 \pm 8.13$ & $164.6 \pm 8.34$ & 0.787 \\
\hline $\begin{array}{l}\text { BMI } \\
\left(\mathrm{kg} / \mathrm{m}^{2}\right)\end{array}$ & $24.28 \pm 0.94$ & $24.36 \pm 1.08$ & $23.97 \pm 1.75$ & 0.691 \\
\hline \multicolumn{5}{|l|}{ Sex, n (\%) } \\
\hline Females & $10(67 \%)$ & $8(53 \%)$ & $10(67 \%)$ & \multirow{2}{*}{0.68} \\
\hline Males & $5(33 \%)$ & $7(47 \%)$ & $5(33 \%)$ & \\
\hline
\end{tabular}

*Significant level is set at alpha level $<0.05$.

\section{Effect of time of application, treatment application and conditions on isokinetic peak torque}

MANOVA of mixed design type revealed that there was non-significant interaction of time of application, treatment application and conditions $(F=1.29, p=0.26)$. There was no significant main effect of time of application $(F=0.59, p=0.73)$. There was a significant main effect of treatment application $(\mathrm{F}=96.2, \mathrm{p}=0.001)$. There was no significant main effect of condition $(\mathrm{F}=1.37, \mathrm{p}=$ 0.26). Table 3 presented descriptive statistics of IKPT.

\section{Within groups comparison}

It revealed a significant decrease in IKPT in the three groups post treatment compared with that pretreatment in placebo and active conditions $(\mathrm{p}<0.001)$. While the percent of decrease of IKPT in 5 minutes, 1 hour and 5 hours groups in placebo condition was $27.88 \%, 31.14 \%$ and $33.13 \%$ respectively, in active condition was $26.89 \%, 28.63 \%$ and $31.93 \%$ respectively, which demonstrated that the 5 minutes group showed the lowest percent of decrease in IKPT compared to the other 2 groups. 
Rageh et al.

\section{Among groups comparison}

It showed a non-significant difference in IKPT at pre and post treatment in placebo and active conditions $(\mathrm{p}>0.05)($ Table 3$)$.

Table 3. Descriptive statistics for isokinetic peak torque, pre- and post-LED, in placebo and active condition of the three groups

\begin{tabular}{llll}
\hline 5 minutes & & $\mathbf{1}$ hour & 5 hours \\
\hline Placebo & & & \\
\hline Pre & $28.62 \pm 13.10$ & $29.22 \pm 6.57$ & $28.46 \pm 11.12$ \\
Post & $20.64 \pm 12.56$ & $20.12 \pm 6.18$ & $19.03 \pm 11.00$ \\
\% of change & $27.88 \%$ & $31.14 \%$ & $33.13 \%$ \\
& $p=0.001$ & $p=0.001$ & $p=0.001$ \\
\hline Active & & & \\
\hline Pre & $28.93 \pm 16.09$ & $28.53 \pm 8.70$ & $28.09 \pm 12.75$ \\
Post & $21.15 \pm 14.71$ & $20.36 \pm 7.19$ & $19.12 \pm 10.27$ \\
\% of change & $26.89 \%$ & $28.63 \%$ & $31.93 \%$ \\
& $p=0.001$ & $p=0.001$ & $p=0.001$ \\
\hline
\end{tabular}

\section{DISCUSSION}

There are few studies concerning photobiomodulation therapy (PBMT) and muscular preconditioning that focused on the effect of different application timing intervals of PBMT in clinical trials, with contradicting results (Rossato, Dellagrana, Sakugawa, Lazzari, Baroni \& Diefenthaeler, 2018; Abreu, Dos Santos, Fonsati, Marques \& Ferraresi, 2020). So, the purpose of this study was to determine the optimal time between light emitting diode (LED) application and elbow flexors exercise and to determine effect of LED on muscle's strength represented by isokinetic peak torque.

The primary findings of this study were that neither of the LED groups could maintain isokinetic torque level in the post test compared to pre-test in the active and placebo conditions significantly, but LED applied 5 minutes before exercise showed the least percent of diminishing isokinetic peak torques in the active condition, compared to the placebo condition, within the group and between groups, irradiated 1 hour and 5 hours prior to the exercise. 
Rageh et al.

To the author's knowledge, the current study is the first randomized controlled trial in human that investigates the time response of LEDT, focusing on studying a specific wavelength within the infrared range, since it was indicated that the light energy can be transferred from 2 to $4 \mathrm{~cm}$ across the skin interface by using diodes with wavelengths extending from 820 to $904 \mathrm{~nm}$ (Enwemeka, 2009; Enwemeka, Parker, Dowdy, Harkness, Harkness \& Woodruff, 2004; Reddy, 2004). Therefore, they are the most appropriate for the management of deep soft tissues.

Another strength of the current study was that, at the beginning of the two sessions, the participants showed similar maximal torque capabilities and underwent the assessment with homogenous performance. Consequently, any variances in the post fatigue values could not be caused by possible pre-existing alterations in the two experimental conditions and the undesirable learning effect from the first and second treatment sessions can be ruled out.

Additionally, multi diode LEDT may have a privilege over single-diode, as they have larger beam divergence, so they do not have to be repositioned as frequently during treatment as the single-diode, while still incorporating a large muscle surface area and application points (Borsa, Larkin \& True, 2013). Therefore, in the current study the multi diode LEDT was used with 120 diodes to irradiate a large number of points of the elbow flexor muscles, in contrast to many studies that relied on irradiating only a few number of points (Junior, Lopes-Martins, Baroni, De Marchi, Taufer \& Manfro, et al., 2009; Leal, Lopes-Martins, Frigo, De Marchi, Rossi \& De Godoi, et al, 2010; Borsa, Larkin \& True, 2013).

One of the unique points in the present study was the use of isokinetic fatigue instead of the isometric protocol most commonly used, as isometric contractions may not be demonstrative of incidence of muscle action and fatigue during human activity (Green, 1995). This exercise procedure has been previously used and replicates the cellular and efficient processes detected with acute sessions of exercise (Borsa \& Sauers, 2000).

The current study focused on evaluating the isokinetic peak torque, as the peak torque variable is addressed as the "golden criterion" estimate in isokinetic testing (Kannus, 1994; Miller, Pierson, Nickols-Richardson, Wootten, Selmon \& Ramp et al., 2006). Additionally, peak torque has been the variable most widely used in the interpretation of isokinetic assessments (Amaral, Marinho, Ocarino, Silva, Souza \& Fonseca, 2014). The 5 minutes group showed a higher capacity to preserve isokinetic peak torque, although not significant, which may be attributed to using several series of fatiguing exercise that veiled comparatively insignificant but noticeable effects. 
Rageh et al.

The extensive inconsistency of findings documented from earlier studies may be due to the wide variability in the application parameters, diverse machines enclosing combined Laser and LED groupings or each type separately, and using PBMT by probes, pads, or clusters of variable sizing. Also, the wide range of parameters used by investigators, such as wavelengths, power, number of treated points, and energy per point. Further probable explanations involve differences in the fatigue provocation protocol type, the nature of different participants, and the different methods of assessment that were applied (Rossato, Dellagrana, Sakugawa, Lazzari, Baroni, Diefenthaeler, 2018; Abreu, Dos Santos, Fonsati, Marques \& Ferraresi, 2020; Beltrame, Ferraresi, Parizotto, Bagnato \& Hughson, 2018). The present study was performed using NIR-LED of $890 \mathrm{~nm}, 60 \mathrm{~J}, 15 \mathrm{~mW}$ per diode, for 57 seconds irradiating 120 points by technique of direct contact overlaying $45 \mathrm{~cm}^{2}$ of the elbow flexor muscles. These parameters were consistent with the most recent recommendations for the enhancement of post-exercise recovery process (Leal-Junior, Lopes-Martins \& Bjordal, 2019).

One of the triggering mechanisms of the fatigue of skeletal muscle is the decline in ATP production within the muscles (Grassi, Rossiter, Zoladz, 2015). It was shown that NIR radiation can promote cellular mitochondrial photochemical and photophysical modifications (Ferraresi, de Brito Oliveira, de Oliveira Zafalon, de Menezes Reiff, Baldissera, de Andrade Perez, et al., 2011; de Brito Vieira, Ferraresi, de Andrade Perez, Baldissera \& Parizotto, 2012). These modifications may initiate amplified mitochondrial membrane potential (MMP) (Passarella, Ostuni, Atlante \& Quagliariello, 1988) and the maturity of giant mitochondria (Manteifel, Bakeeva \& Karu, 1997) that boosted cellular ATP levels. This justifies the fatigue resistance potential of NIR-LED. Although the improved ATP generation produced by PBMT has been extensively recognized in the literature (Ferraresi, de Brito Oliveira, de Oliveira Zafalon, de Menezes Reiff, Baldissera, de Andrade Perez, et al., 2011, de Brito Vieira, Ferraresi, de Andrade Perez, Baldissera \& Parizotto, 2012), there is still a demand for additional explanation of the ideal time interval during which this improvement happens (Rossato, Dellagrana, Sakugawa, Lazzari, Baroni \& Diefenthaeler, 2018).

It has been recorded that there is an increase in all complexes of the electron transport chain (ETC) of the mitochondria, specifically cytochrome c oxidase (CCO) enzyme action or complex IV, following radiation by NIR (Silveira, da Silva, Fraga, Freitas, Streck, Pinho, 2009). PBMT was recorded to excite $\mathrm{CCO}$, starting from 5 minutes to 24 hours following treatment, as per the applied dosage and wavelength (Albuquerque-Pontes, de Paula Vieira, Tomazoni, Caires, Nemeth \& Vanin, et al., 2015). An earlier in-vitro study has revealed that PBMT altered production of ATP and potential 
Rageh et al.

of the mitochondrial membrane in hepatocytes, applying a timing interval of 3 minutes span between irradiation and measurement (Passarella, Casamassima, Molinari, Pastore, Quagliariello \& Catalano et al., 1984).

In this regard, findings of the present study are in harmony with an earlier study which described that loss of muscle strength was diminished by using NIR laser treatment applied 5 minutes prior to exercise (Larkin-Kaiser, Christou, Tillman, George \& Borsa, 2015), and also is consistent with a study that reported no impact of LED employed 30 minutes or 6 hours prior to exercise, on metabolism of aerobic type (Beltrame, Ferraresi, Parizotto, Bagnato \& Hughson, 2018).

On the other hand, there is a conflict between the present results and the results of a study that recommended that the grouping of PBMT was utilized at 2 time intervals; 5 minutes before and 6 hours before the exercise triggered a smaller drop in peak torque values contrasted to placebo, control, and 5 minutes prior to treatment groups (Rossato, Dellagrana, Sakugawa, Lazzari, Baroni \& Diefenthaeler, 2018). This conflict can probably be accredited to the use of collective red and infrared wavelengths at the same time, which possibly gives a privilege to the absorbing light chromophores in the cells (Ferraresi, Parizotto, Pires de Sousa, Kaippert, Huang \& Koiso et al., 2015), predominantly CCO, causing much more ATP generation than individual application of either NIR or red wavelengths (Karu, 1999). On the contrary, the current study aimed to study NIR time reaction, which has not been investigated so far.

From another perspective, it has been reported that LED applied at different time intervals from 5 minutes to 6 hours before exercise showed no effect on torque values (Abreu, Dos Santos, Fonsati, Marques \& Ferraresi, 2020), in spite of using the dose of 60 Joules, which is a highly recommended dose, and LED flexible arrays treating a large extent of elbow flexors (Leal-Junior, Lopes-Martins \& Bjordal, 2019). This could be interpreted by using lower density of energy $\left(0.35 \mathrm{~J} / \mathrm{cm}^{2}\right)$ than the advocated density by Rossato et al. (Rossato, Dellagrana, Lanferdini, Sakugawa, Lazzari \& Baroni, et al., 2016), who claimed that the small-sized and large-sized PBMT clusters showed equally positive outcomes on elbow flexors fatigue, so that it can be deduced that the effectual density of energy varies from $0.99 \mathrm{~J} / \mathrm{cm}^{2}$ to $4 \mathrm{~J} / \mathrm{cm}^{2}$. Taking this factor into account, the present study accredited an energy density of $1.33 \mathrm{~J} / \mathrm{cm}^{2}$, which clarifies the difference in our results from those of Abreu, Dos Santos, Fonsati, Marques \& Ferraresi (2020). 
Rageh et al.

\section{LIMITATIONS}

There is a number of limitations to be considered in the interpretation of the current results. A particular class of muscles was involved in the fatiguing exercise, to precisely control the study, thus this can limit the findings' generalizability to further multidimensional training activities. Moreover, muscle fatigue blood markers as lactate were not measured prior to and following exercise, which is proposed to be done in upcoming studies.

\section{CONCLUSION}

The current study proposes that the most advantageous point of time for NIR LED application is 5 minutes before exercise to augment muscle's potential to resist fatigue. This might facilitate achieving a systematized protocol of PBMT to reduce the unfavorable muscle fatigue consequences that influences workers' and patients' populations production and functioning commonly. Also, this could be valuable for patients through rehabilitation settings, maximizing LED efficacy prior to exercises and enhancing the process of recovery and the rehabilitation effects.

\section{REFERENCES}

1. Abreu, J. S. D. S., Dos Santos, G.V., Fonsati, L., Marques, N. R., \& Ferraresi, C. (2020). TimeResponse of Photobiomodulation Therapy by Light-Emitting Diodes on Muscle Torque and Fatigue Resistance in Young Men: Randomized, Double-Blind, Crossover and PlaceboControlled Study. Photobiomodulation, Photomedicine, and Laser Surgery, 38(12), 750-757. https://doi.org/10.1089/photob.2020.4813

2. Albuquerque-Pontes, G. M., de Paula Vieira, R., Tomazoni, S. S., Caires, C. O., Nemeth, V., Vanin, A. A., ... \& Leal-Junior, E. C. P. (2015). Effect of pre-irradiation with different doses, wavelengths, and application intervals of low-level laser therapy on cytochrome c oxidase activity in intact skeletal muscle of rats. Lasers in medical science, 30(1), 59-66. https://doi.org/10.1007/s10103-014-1616-2

3. Amaral, G. M., Marinho, H. V., Ocarino, J. M., Silva, P. L., Souza, T. R., \& Fonseca, S. T. (2014). Muscular performance characterization in athletes: a new perspective on isokinetic variables. Brazilian journal of physical therapy, 18(6), 521-529. https://doi.org/10.1590/bjptrbf.2014.0047

4. Armstrong, T. J., Buckle, P., Fine, L. J., Hagberg, M., Jonsson, B., Kilbom, A., ... \& ViikariJuntura, E. R. (1993). A conceptual model for work-related neck and upper-limb musculoskeletal disorders. Scandinavian journal of work, environment \& health, 73-84

5. Ballantyne, B. T., \& Shields, R.K. (2010). Quadriceps fatigue alters human muscle performance during a novel weight bearing task. Medicine and science in sports and exercise, 42(9), 1712.

6. Baroni, B. M., Junior, E. C. P. L., De Marchi, T., Lopes, A. L., Salvador, M., \& Vaz, M. A. (2010). Low level laser therapy before eccentric exercise reduces muscle damage markers in humans. European journal of applied physiology, 110(4), 789-796. https://doi.org/10.1007/s00421-010-1562-z 
Rageh et al.

7. Baroni, B. M., Leal Junior, E. C. P., Geremia, J. M., Diefenthaeler, F., \& Vaz, M. A. (2010). Effect of light-emitting diodes therapy (LEDT) on knee extensor muscle fatigue. Photomedicine and laser surgery, 28(5), 653-658.

8. Beltrame, T., Ferraresi, C., Parizotto, N. A., Bagnato, V. S., \& Hughson, R. L. (2018). Lightemitting diode therapy (photobiomodulation) effects on oxygen uptake and cardiac output dynamics during moderate exercise transitions: a randomized, crossover, double-blind, and placebo-controlled study. Lasers in Medical Science, 33(5), 1065-1071. https://doi.org/10.1007/s10103-018-2473-1

9. Bjordal, J. M., Lopes-Martins, R. A. B., Joensen, J., \& Iversen, V. V. (2010). The antiinflammatory mechanism of low level laser therapy and its relevance for clinical use in physiotherapy. Physical Therapy Reviews,15(4), 286-293.

10. Borsa, P., \& Sauers, E. (2000). The importance of gender on myokinetic deficits before and after microinjury. Medicine \& Science in Sports \& Exercise,32(5), 891-896.

11. Borsa, P. A., Larkin, K. A., \& True, J. M. (2013). Does phototherapy enhance skeletal muscle contractile function and postexercise recovery? A systematic review. Journal of Athletic Training, 48(1), 57-67.

12. Calleja-González, J., Terrados, N., Mielgo-Ayuso, J., Delextrat, A., Jukic, I., Vaquera, A., ... \& Ostojic, S. M. (2016). Evidence-based post-exercise recovery strategies in basketball. The Physician and sportsmedicine, 44(1), 74-78.

13. Chaffin, D. B., Andersson, G. B., \& Martin, B. J. (2006). Occupational biomechanics. John wiley \& sons.

14. De Almeida, P., Lopes-Martins, R. Á. B., De Marchi, T., Tomazoni, S. S., Albertini, R., Corrêa, J. C. F., ... \& Junior, E. C. P. L. (2012). Red (660 nm) and infrared (830 nm) low-level laser therapy in skeletal muscle fatigue in humans: what is better? Lasers in medical science, 27(2), 453-458. https://doi.org/10.1007/s10103-011-0957-3

15. De Brito Vieira, W. H., Ferraresi, C., de Andrade Perez, S. E., Baldissera, V., \& Parizotto, N. A. (2012). Effects of low-level laser therapy $(808 \mathrm{~nm})$ on isokinetic muscle performance of young women submitted to endurance training: a randomized controlled clinical trial. Lasers in medical science, 27(2), 497-504. https://doi.org/10.1007/s10103-011-0984-0

16. De Marchi, T., Junior, E. C. P. L., Bortoli, C., Tomazoni, S. S., Lopes-Martins, R. Á. B., \& Salvador, M. (2012). Low-level laser therapy (LLLT) in human progressive-intensity running: effects on exercise performance, skeletal muscle status, and oxidative stress. Lasers in medical science, 27(1), 231-236.

17. Enoka R. M, \& Duchateau, J. (2008). Muscle fatigue: what, why and how it influences muscle function. The Journal of physiology, 586(1), 11-23.

18. Enwemeka, C. S., Parker, J. C., Dowdy, D. S., Harkness, E. E., Harkness, L. E., \& Woodruff, L. D. (2004). The efficacy of low-power lasers in tissue repair and pain control: a meta-analysis study. Photomedicine and Laser Therapy, 22(4), 323-329.

19. Enwemeka, C. S. (2000). Attenuation and penetration of visible $632.8 \mathrm{~nm}$ and invisible infrared $904 \mathrm{~nm}$ light in soft tissues. Laser Therapy, 13(1), 95-101. https://doi.org/10.5978/islsm.13.95

20. Enwemeka, C. S. (2009). Intricacies of dose in laser phototherapy for tissue repair and pain relief. Photomedicine and Laser Surgery, 27(3), 387-393. https://doi.org/10.1089/pho.2009.2503

21. Ferraresi, C., de Brito Oliveira, T., de Oliveira Zafalon, L., de Menezes Reiff, R. B., Baldissera, V., de Andrade Perez, S. E., ... \& Parizotto, N. A. (2011). Effects of low level laser therapy $(808 \mathrm{~nm})$ on physical strength training in humans. Lasers in Medical Science, 26(3), 349-358. https://doi.org/10.1007/s10103-010-0855-0 
22. Ferraresi, C., de Sousa, M. V. P., Huang, Y. Y., Bagnato, V. S., Parizotto, N. A., \& Hamblin, M. R. (2015). Time response of increases in ATP and muscle resistance to fatigue after lowlevel laser (light) therapy (LLLT) in mice. Lasers in medical science, 30(4), 1259-1267. https://doi.org/10.1007/s10103-015-1723-8

23. Ferraresi, C., Dos Santos, R. V., Marques, G., Zangrande, M., Leonaldo, R., Hamblin, M. R., ... \& Parizotto, N. A. (2015). Light-emitting diode therapy (LEDT) before matches prevents increase in creatine kinase with a light dose response in volleyball players. Lasers in medical science, 30(4), 1281-1287. https://doi.org/10.1007/s10103-015-1728-3

24. Ferraresi, C., Kaippert, B., Avci, P., Huang, Y. Y., de Sousa, M. V., Bagnato, V. S., ... \& Hamblin, M. R. (2015). Low-level Laser (Light) Therapy Increases Mitochondrial Membrane Potential and ATP Synthesis in C2C12 Myotubes with a Peak Response at 3-6 h. Photochemistry and photobiology, 91(2), 411-416. https://doi.org/10.1111/php.12397

25. Ferraresi, C., Parizotto, N. A., Pires de Sousa, M. V., Kaippert, B., Huang, Y. Y., Koiso, T., ... \& Hamblin, M. R. (2015). Light-emitting diode therapy in exercise-trained mice increases muscle performance, cytochrome c oxidase activity, ATP and cell proliferation. Journal of biophotonics, 8(9), 740-754. https://doi.org/10.1002/jbio.201400087

26. Fulop, A. M., Dhimmer, S., Deluca, J. R., Johanson, D. D., Lenz, R. V., Patel, K. B., ... \& Enwemeka, C. S. (2010). A meta-analysis of the efficacy of laser phototherapy on pain relief. The Clinical journal of pain, 26(8), 729-736.

27. Grassi, B., Rossiter, H. B., Zoladz, J. A. (2015). Skeletal muscle fatigue and decreased efficiency: two sides of the same coin? Exercise and sport sciences reviews, 43(2), 75-83. https://doi.org/10.1249/JES.0000000000000043

28. Green, H. (1995). Metabolic determinants of activity induced muscular fatigue. Exercise metabolism, 211-256.

29. Green S., Langberg, H., Skovgaard, D., Bülow, J., \& Kjær, M. (2000). Interstitial and arterialvenous $[\mathrm{K}+]$ in human calf muscle during dynamic exercise: effect of ischaemia and relation to muscle pain. The Journal of physiology, 529(3), 849-861.

30. Higashi, R. H., Toma, R. L., Tucci, H. T., Pedroni, C. R., Ferreira, P. D., Baldini, G. S., ... \& Renno, A. C. M. (2013). Effects of low-level laser therapy on biceps braquialis muscle fatigue in young women. Photomedicine and laser surgery, 31(12), 586-594.

31. Junior, E. C. P. L., Lopes-Martins, R. Á. B., Baroni, B. M., De Marchi, T., Taufer, D., Manfro, D. S., ... \& Bjordal, J. M. (2009). Effect of $830 \mathrm{~nm}$ low-level laser therapy applied before highintensity exercises on skeletal muscle recovery in athletes. Lasers in medical science, 24(6), 857.

32. Kannus, P. (1994). Isokinetic evaluation of muscular performance. International journal of sports medicine,15(S 1), S8-S11.

33. Karu, T. (1999). Primary and secondary mechanisms of action of visible to near-IR radiation on cells. Journal of Photochemistry and photobiology B: Biology,49(1), 1-17. https://doi.org/10.1016/S1011-1344(98)00219-X

34. LaBella, C. R., Huxford, M. R., Grissom, J., Kim, K. Y., Peng, J., \& Christoffel, K. K. (2011). Effect of neuromuscular warm-up on injuries in female soccer and basketball athletes in urban public high schools: cluster randomized controlled trial. Archives of pediatrics \& adolescent medicine,165(11), 1033-1040.

35. Lanferdini, F. J., Bini, R. R., Baroni, B. M., Klein, K. D., Carpes, F. P., \& Vaz, M. A. (2018). Improvement of performance and reduction of fatigue with low-level laser therapy in competitive cyclists. International Journal of Sports Physiology and Performance, 13(1), 1422.

36. Larkin, K. A., Martin, J. S., Zeanah, E. H., True, J. M., Braith, R. W., \& Borsa, P. A. (2012). Limb blood flow after class 4 laser therapy. Journal of athletic training, 47(2), 178-183. 
Rageh et al.

37. Larkin-Kaiser, K. A., Christou, E., Tillman, M., George, S., \& Borsa, P. A. (2015). Nearinfrared light therapy to attenuate strength loss after strenuous resistance exercise. Journal of athletic training, 50(1), 45-50. https://doi.org/10.4085/1062-6050-49.3.82

38. Leal, E. C. P., Lopes-Martins, R. Á. B., Frigo, L., De Marchi, T., Rossi, R. P., De Godoi, V., ... \& Bjordal, J. M. (2010). Effects of low-level laser therapy (LLLT) in the development of exercise-induced skeletal muscle fatigue and changes in biochemical markers related to postexercise recovery. Journal of orthopaedic \& sports physical therapy, 40(8), 524-532. https://doi.org/10.2519/jospt.2010.3294

39. Leal Junior, E. C. P., Lopes-Martins, R. A. B., Dalan, F., Ferrari, M., Sbabo, F. M., Generosi, R. A., ... \& Bjordal, J. M. (2008). Effect of 655-nm low-level laser therapy on exercise-induced skeletal muscle fatigue in humans. Photomedicine and laser surgery, 26(5), 419-424. https://doi.org/10.1089/pho.2007.2160

40. Junior, E. C. P. L., Lopes-Martins, R. Á. B., Vanin, A. A., Baroni, B. M., Grosselli, D., De Marchi, T., ... \& Bjordal, J. M. (2009). Effect of $830 \mathrm{~nm}$ low-level laser therapy in exerciseinduced skeletal muscle fatigue in humans. Lasers in Medical Science, 24(3), 425-431. https://doi.org/10.1007/s10103-008-0592-9

41. Leal-Junior, E. C. P., Lopes-Martins, R. Á. B., \& Bjordal, J. M. (2019). Clinical and scientific recommendations for the use of photobiomodulation therapy in exercise performance enhancement and post-exercise recovery: current evidence and future directions. Brazilian journal of physical therapy, 23(1), 71-75. https://doi.org/10.1016/j.bjpt.2018.12.002

42. Maegawa, Y., Itoh, T., Hosokawa, T., Yaegashi, K., \& Nishi, M. (2000). Effects of nearinfrared low-level laser irradiation on microcirculation. Lasers in Surgery and Medicine: The Official Journal of the American Society for Laser Medicine and Surgery, 27(5), 427-437.

43. Manteifel, V., Bakeeva, L., \& Karu, T. (1997). Ultrastructural changes in chondriome of human lymphocytes after irradiation with He-Ne laser: Appearance of giant mitochondria. Journal of Photochemistry and Photobiology B: Biology, 38(1), 25-30. https://doi.org/10.1016/S10111344(96)07426-X

44. Mehta, R. K., \& Cavuoto, L. A. (2017). Relationship between BMI and fatigability is task dependent. Human factors,59(5), 722-733. https://doi.org/10.1177/0018720817695194

45. Miller, L. E., Pierson, L. M., Nickols-Richardson, S. M., Wootten, D. F., Selmon, S. E., Ramp, W. K., \& Herbert, W. G. (2006). Knee extensor and flexor torque development with concentric and eccentric isokinetic training. Research quarterly for exercise and sport, 77(1), 58-63.

46. Miranda, E. F., Vanin, A. A., Tomazoni, S. S., Grandinetti, V. D. S., de Paiva, P. R. V., Machado, C. D. S. M., ... \& Leal-Junior, E. C. P. (2016). Using pre-exercise photobiomodulation therapy combining super-pulsed lasers and light-emitting diodes to improve performance in progressive cardiopulmonary exercise tests. Journal of Athletic Training, 51(2), 129-135.

47. Passarella, S., Casamassima, E., Molinari, S., Pastore, D., Quagliariello, E., Catalano, I. M., \& Cingolani, A. (1984). Increase of proton electrochemical potential and ATP synthesis in rat liver mitochondria irradiated in vitro by helium-neon laser. FEBS letters,175(1), 95-99. https://doi.org/10.1016/0014-5793(84)80577-3

48. Passarella, S., Ostuni, A., Atlante, A., \& Quagliariello, E. (1988). Increase in the ADP/ATP exchange in rat liver mitochondria irradiated in vitro by helium-neon laser. Biochemical and biophysical research communications,156(2), 978-986. https://doi.org/10.1016/s0006291x(88)80940-9

49. Pinheiro, A. L. (2009). Advances and perspectives on tissue repair and healing. Mary Ann Liebert: NY, USA.

50. Reddy, G. K. (2004). Photobiological basis and clinical role of low-intensity lasers in biology and medicine. Journal of clinical laser medicine \& surgery, 22(2), 141-150. 
51. Rossato, M., Dellagrana, R. A., Lanferdini, F. J., Sakugawa, R. L., Lazzari, C. D., Baroni, B. M., \& Diefenthaeler, F. (2016). Effect of pre-exercise phototherapy applied with different cluster probe sizes on elbow flexor muscle fatigue. Lasers in medical science,31(6), 1237-1244. https://doi.org/10.1007/s10103-016-1973-0

52. Rossato, M., Dellagrana, R. A., Sakugawa, R. L., Lazzari, C. D., Baroni, B. M., \& Diefenthaeler, F. (2018). Time response of photobiomodulation therapy on muscular fatigue in humans. The Journal of Strength \& Conditioning Research, 32(11), 3285-3293. https://doi.org/10.1519/JSC.0000000000002339

53. Samoilova, K. A., Zhevago, N. A., Menshutina, M. A., \& Grigorieva, N. B. (2008). Role of nitric oxide in the visible light-induced rapid increase of human skin microcirculation at the local and systemic level: I. diabetic patients. Photomedicine and Laser Surgery, 26(5), 433442.

54. Silveira, P. C., da Silva, L. A., Fraga, D. B., Freitas, T. P., Streck, E. L., \& Pinho, R. (2009). Evaluation of mitochondrial respiratory chain activity in muscle healing by low-level laser therapy. Journal of Photochemistry and Photobiology B: Biology, 95(2), 89-92. https://doi.org/10.1016/j.jphotobiol.2009.01.004

55. Weerapong, P., Hume, P. A., \& Kolt, G. S. (2005). The mechanisms of massage and effects on performance, muscle recovery and injury prevention. Sports medicine, 35(3), 235-256.

\section{AUTHOR CONTRIBUTIONS}

All authors listed have made a substantial, direct and intellectual contribution to the work, and approved it for publication.

\section{CONFLICTS OF INTEREST}

The authors declare no conflict of interest.

\section{FUNDING}

This research received no external funding.

\section{COPYRIGHT}

(C) Copyright 2021: Publication Service of the University of Murcia, Murcia, Spain. 